\title{
Prenatal of Pregnant Adolescents Performed by Nurses in Primary Health Care
}

\author{
Vania Maria Alves de Sousa ${ }^{*}$, Dafne Paiva Rodrigues ${ }^{2}$, Maria Veraci Oliveira Queiroz ${ }^{2}$, \\ Martha Campos Moura Fé3, Dean Douglas Ferreira de Olivindo ${ }^{1}$ \\ ${ }^{1}$ Santo Agostinho University, Teresina, Brazil \\ ${ }^{2}$ State University of Ceará, Fortaleza, Brazil \\ ${ }^{3}$ Secretary of Health of the City of Limoeiro do Norte, Ceará, Brazil \\ Email: *vm.24@hotmail.com, dafne.rodrigues@uece.br, veracioq@hotmail.com,martha_mourafe@yahoo.com.br, \\ dean_olivindo@yahoo.com.br
}

How to cite this paper: de Sousa, V.M.A., Rodrigues, D.P., Queiroz, M.V.O., Fé, M.C.M. and de Olivindo, D.D.F. (2016) Prenatal of Pregnant Adolescents Performed by Nurses in Primary Health Care. Open Journal o1 Nursing, 6, 833-840. http://dx.doi.org/10.4236/ojn.2016.610082

Received: August 18, 2016

Accepted: October 8, 2016

Published: October 11, 2016

Copyright $\odot 2016$ by authors and Scientific Research Publishing Inc. This work is licensed under the Creative Commons Attribution International License (CC BY 4.0).

http://creativecommons.org/licenses/by/4.0/ (c) (i) Open Access

\begin{abstract}
This study aims to identify the actions performed by nurses of the Family Health Strategy with the pregnancy cycle of adolescents and analyze if the actions developed by these nurses are focused on risk prevention in pregnancy and childbirth. It is a qualitative and exploratory research in basic health units with 12 nurses. A semi-structured interview technique was applied, and the speeches were analyzed using content analysis. In the analysis of the results, it was identified two thematic categories in which it was noted that nurses during the prenatal make the reception of pregnant adolescents differently and conduct guidelines on examination, signs and symptoms of possible complications during the pregnancy and still emphasize the importance of educational activities as groups of pregnant women to be a chance of coexistence and exchange of experiences, doubts, and anxieties among themselves. It is concluded that the care provided by nurses is fundamental for the pregnant adolescents having prenatal with more quality.
\end{abstract}

\section{Keywords}

Pregnancy in Adolescence, Nursing Care, Primary Health Care

\section{Introduction}

Adolescence is a period of transition between childhood and adulthood in which there is a quickly physical, cognitive, social and emotional maturation, to the extent that the boy is preparing to be a man and the girl to be a woman. It is difficult to set the limits of the adolescence, but this period is seen customarily starting with the gradual appearance 
of secondary sexual characteristics, with approximately 11 or 12 years old and ending with cessation of body growth, with 18 to 20 [1].

In this complex phase of life, teenagers are susceptible to situations with the greatest exposure to conflicts, discoveries, and expectations, requiring the guidance of a multidisciplinary team to help them overcome this important period of their lives. If it does not, there is a possibility of these adolescents be exposed to particular hardships in this age group, such as early pregnancy, sexually transmitted diseases, several accidents, illicit drug use, abuse, domestic violence, among many other problems [2].

The risk approach appears strongly associated with this age group through expressions such as pregnancy risk, for Sexually Transmitted Diseases (STDs) and AIDS and using illegal drugs. Thus, the general risk seems to define and circumscribe negatively this period of life, generating expressions, actions, and attitudes toward adolescents [3].

Adolescence is characterized by a series of transformations that characterize this complex period of transition, which can become even more difficult when a pregnancy occurs. To become a mother, the teenager interrupts the natural course of her age and faces numerous responsibilities. Teenage pregnancy becomes a transformative phenomenon that causes changes in the environment in which these young people are inserted [4].

This research sought to answer the following question: What are the health actions taken by nurses in primary care in the teenage in the pregnancy period?

\section{Objectives}

This research aimed to identify the actions performed by nurses of the Family Health Strategy with adolescents in the pregnancy cycle and analyze if the actions developed by these nurses are focused on risk prevention in pregnancy and childbirth.

\section{Methods}

\subsection{Place}

The research was conducted in the Basic Health Units in the city of Teresina that are part of the Regional Health of the southern zone of the municipality.

\subsection{Inclusion and Exclusion Criteria}

Inclusion criteria were nurses working in primary care in the Family Health Strategy and made a prenatal consultation for at least 1 year with adolescents and to accept joining the research. The exclusion criteria were nurses not performing prenatal consultation for at least 1 year in the Family Health Strategy and adolescents who did not accept to participate.

\subsection{Risks}

The research has no physical or psychological risks to participants.

\subsection{Contributions of the State}

Research aimed to analyze the actions developed with adolescents in primary care 
appears every day to seek solutions to problems, for example, teenage pregnancy. It is hoped that this study is a reference material and contributes to direct managers on planning actions that will provide a healthy and productive life to adolescents.

\subsection{Data Collection}

Data collection occurred in the Basic Health Units (BHU) in Teresina. Data collection was carried out between September and October 2013. The study included twelve nurses working in the Family Health Strategy of the Teresina and monitor adolescents during the prenatal period. The sample closure was given by theoretical saturation, which is a continuous process of analyzing the data, taking place from the start of data collection. In this method the collection is closed when it is observed that little new information appears A semi-structured interview containing a guiding question to answer the question of this study was carried out: "What are the actions that you develop with teenagers during the pregnancy period?" Accompanied by a structured form to characterize the participants, a pre-test to improve the instrument was applied previously to the collection data. The interviews were previously scheduled with nurses working in the basic health units being carried out by researchers in the nursing. The average time of interview offices took 30 minutes.

\subsection{Data Analysis}

For processing and analyzing the data, the thematic content analysis technique was used through three chronological poles: the pre-analysis; exploration of the material and the processing of the results; inference and interpretation [5]. Initially, there was the constitution of the corpus, the perusal of all the material, the reporting units being identified, encoding them to group them together by similarities and thus preparing the analytical categories. Respondents were referred as E1, E2, and so on to protect the anonymity of the participants.

\subsection{Ethical Aspects}

This project was developed by Resolution 466/12 of the National Health Council (CNS), which refers to research human beings. The project was sent to the ethics committee of the municipality of Teresina Municipal Health Foundation for authorization of collection. This survey of data was approved by the Research Ethics Committee of the State University of Ceará in the number of CAAE-11867612.0.0000.5534 Protocol on 04 September 2013. The subjects were interviewed after accepting to participate in the research by signing the Inform Agreement Consent.

\section{Result and Analysis}

Most nurses were female and the average age of survey participants was 30 years to 56 years old and from 12 nurses interviewed, 10 of them have 10 or more years of training and most have been working in the family health strategy for at least 10 years noticing that it is a population that already has plenty of experience in the Family Health Strategy. 
Two categories were listed to facilitate the understanding of health actions carried out by the Family Health Strategy nurses with adolescents during the prenatal.

\subsection{Differentiated Prenatal Care for Adolescents}

In this category, it was observed that the professionals interviewed have a concern to a different prenatal care, given that it is a pregnant adolescent needing careful attention, emphasizing the importance of family support and her partner in this moment of findings and questions for them. They consider that at the time of consultation only the scientific part should not be prioritized. Listening and host for this pregnant should be involved in the consultation creating a bond with the professionals who work in the team and not abandon the prenatal as can be seen in the following excerpts from the interviews:

I try to have a view of teen life if she lives with her parents if the current pregnancy was accepted by the family. What she is going through at that time, which the living conditions are, the prospects for life if she will want to raise the child or not (E6).

It is a very time-consuming consultation because they have many questions. Even those adolescents who already have a child, they are full of doubts, very inexperienced. So, I prioritize the orientation of pregnant women. Another care I have is to make a more detailed medical history due to a requirement of the Ministry of Health saying that adolescence is a risk factor for pregnancy (E2). I try to dispense with a more careful look at this woman. I try to keep a rapprochement with a teenager to win greater trust her and her family (E7).

The nursing consultation on women pregnant gives the opportunity to treat the individual in a general context and analyze their physical, psychological and social aspects. It is an occasion for dialogue when nurses and pregnant women can set goals and objectives to be achieved, among them educational activities to a woman in pregnancy process and monitoring the development of pregnancy [6].

Adolescents feel less valued by the family, especially in cases where the family reacted badly to the news of pregnancy. Most of them have low self-esteem, high levels of stress, depressive symptoms and psychological distress. Thus, to feel understood and supported in this difficult phase of their lives, the pregnant adolescent need a space to express and share feelings, doubts, and fears, even if the idle time when waiting for prenatal consultation [7]. During the interviews, it was observed that some nurses had this concern whether the family accepted or not pregnancy of this teenager.

Doctors and nurses have a key role in the care of a pregnant adolescent with distinct characteristics of the adult pregnant. As members of the support network for women, they need to understand the physical, emotional and social changes experienced by teenagers, the resources that they have and what their ways of coping with these situations [3].

During the interview participants reported health actions that developed in prenatal 
care as we can see in the following reports:

In prenatal consultation, I guide on hygiene, feeding, breastfeeding. Forward to the dentist and have scheduled leave cytology. After the 1st consultation team makes a home visit and sees the family context and from there they make the necessary interventions to make the visit because the team approaches the reality. Moreover, this visit is just done for pregnant adolescent (E8).

In the consultation, I ask all the tests, examine the mother, guide on uterine growth, speak what is the reference maternity also guiding about eating what they should do and what they should do at least six prenatal consultations is recommended by the Ministry of Health. I also speak about the indiscriminate use of medication without a prescription, the importance of using ferrous sulfate and folic acid, immunization regarding vaccines $\mathrm{Dt}$ and Hep $\mathrm{B}$ and also on the delivery signals (E12).

During the consultation, I request all routine prenatal exams. I guide on immunization, breastfeeding, danger signs such as bleeding and loss of amniotic fluid, breast care, and nutrition (E10).

So, the fact that they are teenagers, I emphasize more in the guidelines during prenatal consultations. Also, I guide on the child's card, the $1^{\text {st }}$ child consultation and also on the return visit after delivery to do an evaluation (E11).

The pregnant adolescent expects prenatal care above their needs clarification on the gestational process and guides for the care to ensure a healthy pregnancy and a safe delivery. She waits still receive support for coping with personal problems and get the confidence not to be influenced by contradictory information, usually obtained in their living circle [8].

Professionals who accompany women in prenatal care, including nurses, should elaborate pregnant women care plan, according to the identified and prioritized needs, establishing interventions, guidance, and referrals to reference services, promoting interdisciplinarity of actions with medicine, dentistry, nursing, social work and psychology. It is important that health professionals communicate with pregnant women to include other professional and their need monitoring to prenatal care. This approach establishes links are transmitting confidence to women, reducing anxiety and making the mother feel valued. A multidisciplinary team with good interpersonal relationships has greater autonomy to coordinate activities aimed at pregnant women, from the beginning of prenatal care to the postpartum period [9].

\subsection{Inclusion of Pregnant Teenagers in Educational Groups}

When nurses reflect on their practices, they highlight the importance of educational groups of pregnant women, such as a moment of teenagers share information with other adult pregnant women and even among them, learning from the various topics discussed in groups and asking questions in a different environment that the consultation room as mentioned in the following statements: 
There is a project here that is called Project Welcome to Life. A health education week is done with adolescents and this week the team focused on family planning to the issue of pregnancy and throughout the period of pregnancy that goes from labor to the postpartum period. On the last day, we took the pregnant women in the maternity ward to know the environment in which will be done the delivery and offer a trousseau as an incentive for pregnant women that attend the course (E1).

I do the inclusion of it in the pregnant group because I think that the exchange of experiences with other pregnant teens is not important, then it is included in the group of other women (E10).

At this moment, we are not having educational group activities with pregnant women. We are just doing the nursing consultation. They ask me when the pregnant group will start, and I answer soon because I think it is very important that exchange of experience between them (E11).

Unfortunately, we do not have health education groups because our physical structure does not give us the possibility to carry out a group for lack of space. I know that these health education groups are important at this time of life of pregnant women (E5).

Nurses recognize the importance of meetings of the group of pregnant women and some regret for not having a physical structure to hold these meetings in their basic health units. Although the ESF priorities promotion and recovery of health of the individual and his family, given effecting a new dynamic of work, providing comprehensive and quality care to the population, it became clear how difficult it is to conquer the audience for this process job. One obstacle that exists in the care of the nurse is the professional distance with everyday pregnant, her family and other social factors that are part of their daily lives. Thus, the reality experienced by the nurse in the prenatal context requires the creation of the link as a unique step to quality care.

Starting from the assumption that humanistic education is a dialogical-dialectical process in which all teach and learn, the relationships established between health professionals and service users, are pedagogical relationships [10]. In this sense, prenatal is shown as a field conducive to the development of education as a dimension of the care process.

Educational activities in health, developed in collective contexts and with the participation of individuals in common life situation, may be a preferred method of empowerment of individuals through a mutual process of teaching and learning. The host and the bond produced in these group interventions are also contributors to the production of the individual's autonomy in health. Promoting reflections focused on the construction, related to the meanings and reinterpretation of pregnancy experiences and the sense of responsibility of pregnant adolescents make them subject to the care process of them and their children. The wealth of this practice is to promote decision-making "conscious" for pregnant adolescents [11]. Although the ESF priorities promotion and recovery of health of the individual and her family, given effecting a 
new dynamic of work, providing comprehensive and quality care to the population, it became clear how difficult it is to conquer the audience for this process. However, it is insisted on the formation of the group of pregnant women as it is in this dynamic environment that the promotion of full individual, collective health of pregnant women can be performed by the interactions and sharing among subjects with experiences/common experiences. Join group allows a woman to be pregnant-multiplier of knowledge, and this becomes an important strategy to promote healthy pregnancy and delivery and postpartum period [6].

\section{Final Considerations}

The study found that the actions developed by nurses were essential aspects that must exist in the relationship health professional and patients, such as conversation, listening, sharing ideas, demonstration of concern and expression of affection, attention to doubts and anxieties and also other aspects that are valued in holistic care.

The importance of educational groups as a moment of encounter where teens share their doubts, anxieties and experiences are highlighted also being a time to promote health education through the guidelines and actions performed. Nurses have a key role in the prenatal care of pregnant adolescents, to work in the family health strategy with health promotion and disease prevention, thus providing a differentiated service by creating the bond and the host promoting health care free of harm to the mother and her child.

\section{Conclusion}

I conclude that the care provided by nurses in primary care is very important for adolescents during the prenatal since the care and guidelines for adolescents are important to avoid complications during pregnancy, childbirth and postpartum providing quality care for mother and son. The study has the limitation of not proof of health actions reported by respondents considering that the object of study was limited to analyzing the health actions of the nurses informed through the same interview.

\section{References}

[1] Hockenberry, M.J. (2014) Wong Pediatric Nursing Fundamentals. 9a edição, Mosby Elsevier, Rio de Janeiro.

[2] Malagutti, W. and Bergo, M.A. (2009) Adolescents: A Multidisciplinary Approach. 1 ${ }^{\mathrm{a}}$ edição, Martinari, São Paulo.

[3] Buendgens, B.B. and Zampieri, M.F.M. (2012) Pregnant Teen in Doctors and Nurses Perception of Primary. Escola Anna Nery, 16, 64-72.

[4] Fernandes, A.O., Júnior, H.P.O. and Gualda, D.M.R. (2012) Teenage Pregnancy: Perceptions of Mothers of Young Pregnant Women. Acta Paulista de Enfermagem, 25, 55-60. http://dx.doi.org/10.1590/S0103-21002012000100010

[5] Bardin, L. (2011) Content Analysis. 4a edição, Edições70, Lisboa.

[6] Lima, S.S. (2013) Nursing Prenatal Low Risk in the Family Health Strategy. Aquichan, 13, 261-269. http://dx.doi.org/10.5294/aqui.2013.13.2.11 
[7] Alves, A., Albino, A.T. and Zampieri, M.F.M. (2011) A Look of Teenagers about the Changes in Pregnancy: Promoting Mental Health in Primary Care. Revista Mineira de Enfermagem, 15, 545-555.

[8] Vieira, S.M., Bock, L.F., Zocche, D.A. and Pessota, C.U. (2011) Perception of Mothers on Assistance Provided by the Health Team Prenatally. Texto Contexto Enfermagem, 20, 255262. http://dx.doi.org/10.1590/S0104-07072011000500032

[9] Melo, M.C.P. and Coelho, E.A.C.(2011) Completeness and Care to Pregnant Adolescents in Primary Care. Revista Ciência \& Saúde Coletiva, 16, 2549-2558. http://dx.doi.org/10.1590/S1413-81232011000500025

[10] Freire, P. Pedagogy of the Oppressed.(2011) 50 edição, Paz e Terra,São Paulo.

[11] Santos, M.M.A.S., Saunders, C. and Baião, M.R. (2012) The Relationship between Health Professionals and Pregnant Adolescent: Distancing and Approximations of a Full Practice and Humanized. Revista Ciência \& Saúde Coletiva, 17, 775-786.

http://dx.doi.org/10.1590/S1413-81232012000300025

Submit or recommend next manuscript to SCIRP and we will provide best service for you:

Accepting pre-submission inquiries through Email, Facebook, LinkedIn, Twitter, etc. A wide selection of journals (inclusive of 9 subjects, more than 200 journals)

Providing 24-hour high-quality service

User-friendly online submission system

Fair and swift peer-review system

Efficient typesetting and proofreading procedure

Display of the result of downloads and visits, as well as the number of cited articles Maximum dissemination of your research work

Submit your manuscript at: http://papersubmission.scirp.org/

Or contact ojn@scirp.org 